essential. M. E. Avery ${ }^{2}$ has already shown in lambs that the administration of hydrocortisone induces production of surfactant. Could the epidemiological observation of a low incidence of respiratory distress syndrome in premature infants born to heroin-addicted mothers ${ }^{16}$ be a fortuitous example of such induction in man?

1 Schaffer, A. J., and Avery, M. E., in Diseases of the Newborn, 3rd edn. p. 93. Philadelphia, W. B. Saunders, 1971 .

Scopes, J., in Recent Advances in Paediatrics, ed. D. Gairdner and D. Hull, 4th edn., p. 89. London, Churchill, 1971 .

- Gairdner, D., in Recent Advances in Paediatrics, ed. D. Gairdner, 3rd edn., p. 54. London, Churchill, 1965.

Scopes, J., British fournal of Hospital Medicine, 1970, 3, 579

- Reynolds, E. O. R., Roberton, N. R. C., and Wigglesworth, J. S., Pediatrics, $1968,42,758$.

- Gandy, G., Jacobson, W., and Gairdner, D., Archives of Disease in Childhood, 1970, 45, 289.

Gluck, L., Landowne, R. A., and Kulovich, M. V., Pediatric Research, $1970,4,352$.

Gluck, L., et al., American fournal of Obstetrics and Gynaecology, 1971, 109,440 .

Whitfield, C. R., Chan, W. H., Spro

10 British

Bhagwanani, S. G., Fahmy, D., and Turnbull, A. C., Lancet, 1972, 1, 159

12 Buckingham, S., Heinemann, H. O., Sommers, S. G., and McNary, W. F., American fournal of Pathology, 1966, 48, 1027 .

13 Lind, T., and Billewicz, W. Z., British fournal of Hospital Medicine, 1971, 5,681 .

14 Boughton, K., Gandy, G., and Gairdner, D., Archives of Disease in Childhood, 1970, 45, 311 .

15 Casparis, A. W.-de, et al., British Medical fournal, 1971, 3, 144.

16 Glass, L., Rajegowda, B. K., and Evans, H. E., Lancet, 1971, 2, 685.

\section{Predicting Coronary Artery Disease}

It is becoming clear that there is no single cause of the high incidence of coronary artery disease in developed countries. The Framingham study in the U.S.A. showed that hypertension greatly increases the risk of its developing, and there is also considerable evidence that smoking cigarettes and a positive family history of arterial disease do so. In the last few years interest has risen in the elaborate analysis of plasma lipids other than cholesterol, and in younger patients especially there is some evidence that hyperlipidaemias predispose to the development of coronary artery disease. ${ }^{1-3}$ Hyperlipidaemias sometimes produce physical signs, in particular xanthelasmata, or yellowish spots in the eyelids, and may be associated with the development of a corneal arcus.

A recent study from Cambridge ${ }^{4}$ attempts to quantify the relative importance of known predisposing factors in the medical, personal, and family history of patients and in the observable physical signs in order to produce an index of discrimination between patients with and without coronary thrombosis. Approximately 100 patients with coronary thrombosis were compared with a similar number of control men of similar age whose names were obtained from the regional blood transfusion register. In each group an estimate was made of smoking and dietary habits, family history, physical characteristics, blood pressure, and plasma lipid fractions.

Diastolic blood pressure proved the best discriminator, and in decreasing order of importance were the presence of corneal arcus, degree of baldness (increased baldness being associated with coronary artery disease), presence of xanthelasmata, family history of hypertension, number of cigarettes smoked, plasma cholesterol, plasma triglycerides, and low-density lipoproteins. Statistical analyses of these characters enabled patients to be separated from controls, but the disappointing feature of it was the fact that more than half the patients fell within the range of the controls.
Thus even when all the information was taken into account its predictive value was weak. Furthermore, this discrimination was the best available from the data in this series, and it might be less on another series. Another problem in any analysis of this sort is that the controls without clinically manifest coronary artery disease may have had almost as bad disease as the patients. Further, people who volunteer to give blood are perhaps emotionally more stable than average and therefore not fully representative of the whole population. The importance of such factors as cigarette smoking, which was almost as common in controls as in patients, is difficult to evaluate by a study such as this, unless one has for comparison a group of people who have not smoked cigarettes.

But despite these reservations the investigation is useful in practical terms to a doctor called upon to advise a patient. It is of course useless to tell a patient to grow hair on his head or to remove his arcus. Nor will reducing his blood pressure prevent coronary disease, for we know from many previous studies 56 that, though hypertension predisposes to coronary artery disease, lowering the blood pressure does not reduce the chance of its developing. At best a doctor asked by a patient to assess his chances of developing coronary thrombosis can make only a rough guess. If the person concerned is muscular, obese, carries much responsibility and works long hours, smokes heavily, takes little exercise, is bald, has xanthelasmata, an arcus, a raised blood pressure, and his parents had arterial disease, he would obviously be at high risk. If his physical build, personal habits, blood pressure, and other attributes were the opposite, he would have a low risk.

If a patient with many known adverse factors were to ask for advice on preventing coronary disease, what should his doctor say? The evidence of prospective and retrospective studies indicates that the patient should keep his weight somewhat below average, eat as little as possible of known cholesterol-raising foods such as eggs, shell-fish, and animal fats, stop smoking cigarettes, and take plenty of light exercise. Frank hyperlipidaemias should be treated, where appropriate, with drugs (e.g., clofibrate). But it must be admitted that much of this advice is based on guesswork and that one could probably find world authorities to take exception to virtually every one of the recommendations. It is unfortunate that recipes for health seem to be so negative, but the results from the Cambridge study certainly underline the extent of our ignorance about the causes of occlusive arterial disease.

\footnotetext{
1 Keys, A., in Cowdrey's Arteriosclerosis, ed. H. T. Blumenthal, 2nd ed. Springfield, Thomas, 1967.

Schilling, F. J., Becker, W. H., and Christakis, G., Circulation, 1966, 33, Suppl. III, 28.

3 Rifkind, B. M., Lawson, D., and Gale, M. J., fournal of Atherosclerosis Research, 1968, 8, 167.

Cotton, S. G., Nixon, J. M., Carpenter, R. G., and Evans, D. W., British Heart fournal, 1972, 34, 458.

5 Beem, J. R., in Hypertension, ed. J. H. Moyer. Philadelphia, Saunders, 1959.

6 Hood, B., Björk, S., Sannerstedt, R., and Angervall, G., Acta Medica Scandinavica, 1963, 174, 393.
}

\section{Scrotal Cancer Continues}

The risk of scrotal cancer to metal workers who use automatic lathes was highlighted in 1968 by a case 2 in which the widow of a toolsetter who died from the disease was awarded damages of $£ 10,000$. The risk of skin cancer from 